\title{
Introduction: historical geographies of science - places, contexts, cartographies
}

\author{
SIMON NAYLOR*
}

\begin{abstract}
This paper outlines the contours of a historical geography of science. It begins by arguing for the relevance of spatially oriented histories of scientific thought and practice. The paper then considers three different historical geographies of science: those concerned with the places and spaces of science, those that detail the spatial contexts of scientific endeavour, and those that analyse the internal 'cartographies' of scientific theories and methods. The paper concludes with a discussion of other possible avenues of investigation in this field.
\end{abstract}

Scientific knowledge is made in a lot of different places. Does it matter where? Can the location of scientific endeavour make any difference to the conduct of science? And even more important, can it affect the content of science? In my view the answer to these questions is yes. ${ }^{1}$

So begins David N. Livingstone's meditation on the geographies of science. Livingstone's book is an extended defence of his contention on page 1, although it is probably fair to say that much has already been done to put this particular argument to rest. Livingstone himself, along with a cast of other historical geographers, historians and sociologists, has laboured over the past fifteen years or so to cement the claim that science should be treated like any other form of knowledge; that is, as 'a cultural formation, embedded in wider networks of social relations and political power, and shaped by the local environments in which its practitioners carry out their tasks'.2 Livingstone has produced a number of papers that have argued for a more spatially sensitive history of science. Acknowledging in 1995 that historians of science were increasingly taking account of spatial issues, he nevertheless noted, somewhat damningly, that historical geographers had 'remained oblivious' to this turn of events. This lacuna was even present, he contended, in geographers' treatment of the history of their own discipline. ${ }^{3}$

* School of Geographical Sciences, University of Bristol, University Road, Bristol, BS8 1SS, UK.

Thanks to Janet Browne, Crosbie Smith, Simon Schaffer and Trish Hatton for their editorial and administrative work on this issue; to all those who acted as referees, often under tight deadlines; and of course to all the authors. Thanks also to Olivier Milhaud, David Livingstone and Simon Schaffer for their comments on this introductory essay.

1 D. N. Livingstone, Putting Science in Its Place: Geographies of Scientific Knowledge, Chicago, 2003, 1.

2 D. N. Livingstone, 'Reading the heavens, planting the earth: cultures of British science', History Workshop Journal (2002), 54, 236. Emphasis added.

3 D. N. Livingstone, 'The spaces of knowledge: contributions towards a historical geography of science', Environment and Planning D: Society and Space (1995), 13, 5. See also the introduction to the issue: N. Thrift, F. Driver and D. N. Livingstone, 'The geography of truth', Environment and Planning D: Society and Space (1995), 13, 1-3. 
A series of persuasive interventions by geographers since 1995 has done much to rectify the situation in historical geography. ${ }^{4}$ Livingstone's latest book, a quote from which opened this paper, is the most recent and sustained contribution to this movement. ${ }^{5}$ In it he positions a geography of science in opposition to the general perception that science is placeless, that science is in fact a triumph over place. For instance, Livingstone argues that the laboratory has come to epitomize the scientific success story precisely because it lacks any local connotations, for as he reminds us, it is now commonly held that any science that is local has got to have something wrong with it. ${ }^{6}$ Livingstone takes exception to this, arguing instead that place is absolutely central to scientific knowledge and practice, the remainder of the book illustrating the provincial nature of this seemingly universal endeavour.

Livingstone's investment in a historical geography of science has begun to show returns, with a real growth in the number of studies by geographers in this area (and we will return to these later). However, reception of his and others' arguments has not always been entirely uncritical. Beyond the more predictable dismissal of science studies by its detractors in the sciences, there has also been a questioning of the precise form of the argument by those otherwise sympathetic to the field. Steven Shapin's review of Livingstone's Science, Space and Hermeneutics is a case in point. ${ }^{7}$ Shapin takes issue with Livingstone's tendency to treat geography as a 'factor' - in similar manner to cultural values, gender or national identity, say - that can come into play to influence the development of science. However, rather than something that might influence the progress of scientific knowledge, Shapin asserts that space must always be a 'necessary condition for there to be such a thing as science'. In other words, geography, 'like temporality or embodiment', is a necessary prerequisite for science to even take place at all. To claim then that science has a geography is perhaps obvious and unexceptional. 'Where else could science take place but in places', queries Shapin, 'and how else could it travel but across spaces?'.

Shapin's observation is far from a dismissal of a historical geography of science. Whilst he asserts that geography should be viewed as ubiquitous to life in general and science in particular Shapin also argues that it is entirely possible to apprehend science from a geographical perspective. Demonstrating that science can be understood geographically should therefore not be viewed as an end in itself, but as the basis upon which rich empirical stories can be built. A historical geography of science is a partial perspective on science but is nonetheless one that can shed light on certain aspects of its lifeworld. Of course, both Shapin's and Livingstone's point goes further than this. It is

\footnotetext{
4 See, for instance, S. Shapin, 'Placing the view from nowhere: historical and sociological problems in the location of science', Transactions of the Institute of British Geographers (1998), 23, 5-12; D. N. Livingstone, 'Putting Geography in its Place', Australian Geographical Studies (2000), 38, 1-9; idem, 'Making space for science', Erdkunde (2000), 54, 285-96; idem, Science, Space and Hermeneutics (Hettner-Lectures 5), Heidelberg, 2002; C. Withers, Geography, Science and National Identity: Scotland since 1520, Cambridge, 2001.

5 Livingstone, op. cit. (1).

6 Livingstone, op. cit. (1), 1.

7 S. Shapin, review of Livingstone's Science, Space and Hermeneutics, in BJHS (2003), 36, 89-90.

8 Shapin, op. cit. (7), 90.
} 
not simply the case that science can be spatialized; it is also that science itself creates spaces and places for its own activities and in turn spatializes the world in a wide variety of ways. In reference to both Shapin and Livingstone, then, I use the remainder of this Introduction not only to consider the ways a historical geographical perspective can open out science in particular ways, but also to demonstrate the geographies that science makes. In doing so I will refer to a body of work that has argued the case for both agendas. I will certainly not be making exclusive use of work by historical geographers; many historians, sociologists and anthropologists have produced exemplary historical geographies of science, although they might not label them as such. I must admit, though, to a partial range of examples from the literature, with many of the papers highlighted focusing on the British context and on the history of the natural sciences.

The remainder of the paper will consider three geographies of science. The first section will examine work on the micro-geographies of science: the intimate although often mundane spaces in which scientists have gone about their work. Next I move on to look at science and its contexts, including the city, the region and the nation. The third section focuses on a more general and perhaps more abstract set of geographies, those that help define the contours of science itself - what we might term 'cartographies' of science. The conclusion considers avenues for other possible geographies of science.

\section{Placing science}

As Livingstone notes in his Afterword to this special issue, there has been something of a 'geographical turn' in science studies of late. In particular, it has become increasingly accepted in the field that place plays a major role in the development of particular sorts of science, not to mention the development of particular sorts of scientist. An early key contribution is Shapin's work on the place of experiment in seventeenth-century England. ${ }^{9}$ In his analysis of the sites associated with the experimental work of the early Royal Society Shapin maps out the intimate 'connections between empiricist processes of knowledge making and the spatial distribution of participants, pointing to the ineradicable problem of trust that is generated when some people have direct sensory access to a phenomenon and others do not'. ${ }^{10}$ Shapin argues that the laboratory provided a new space for the public witnessing of empirical matters of fact and was therefore important in the advance of a reformed natural philosophy. However, rights of entry to these sites were highly circumscribed. Access, Shapin notes, 'was achieved in a highly informal manner, through the tacit system of recognition, rights, and expectations that operated in the wider society of gentlemen'. ${ }^{11}$ There was, then, a clear social geography to the operation of England's early modern experimental philosophy.

9 S. Shapin, 'The house of experiment in seventeenth-century England', Isis (1988), 79, 373-404.

10 Shapin, op. cit. (9), 374.

11 Shapin, op. cit. (9), 389. 
Seventeenth-century England was not the only place where geography played an active role in shaping science and its participants. Simon Schaffer develops a similar analysis of physics laboratories in nineteenth-century Britain. Whilst seemingly contributing to universal matters of fact, Schaffer highlights their highly localized and socialized nature. ${ }^{12}$ The introduction of the physics laboratory into the conservative British university required it to be insulated from outside disturbance to make its measures count everywhere ... and it had to be fitted into academic culture lest its workshop practice pollute clerical life'. ${ }^{13}$ The mobilization - both figuratively and literally - of the model of the country house was a partial solution to this problem and, Schaffer argues, explains the socially 'privileged and carefully demarcated milieu' of physics laboratories during this period:

If laboratory physics can claim to secure the 'view from nowhere' which allows its work easily to escape the trammels of local context, this is in part because of its peculiar connexion with the putatively tranquil fantasy and strenuously engineered reality of a place in the country. ${ }^{14}$

Other scientific spaces have received similar levels of analysis. Dorinda Outram has demonstrated the ways in which the museum became a key site for the working out of different approaches to the science of nature. Discussing Paris's Muséum national d'histoire naturelle, Outram highlights how Georges Cuvier and Jean Baptiste Lamarck fought out their scientific rivalries spatially. Cuvier wanted more space given over to comparative anatomy and felt that too much was dedicated to the zoological collections; a clash, Outram claims, 'which mirrored their debate over the importance of work on the living animal, or the dead specimen divorced from habitat' ${ }^{15}$

The fraught relationship between the laboratory and another scientific space, the field site, has been the subject of Robert Kohler's work. Rather than two scientific places diametrically opposed to one another, Kohler argues that they are the two sides of a permeable frontier. Whilst all sorts of borrowings and crossings occur over this border, the lab and the field can be separated by their attitudes to place. Laboratories, Kohler argues, attempt to strip themselves of context and variation. They aspire to simplification and standardization, to be 'places apart from the world - placeless places'. ${ }^{16}$ Field sites, on the other hand, embrace place: 'Field practices are not the placeless practices of labs but practices of place' ${ }^{17}$ In other words, when the local conditions of a laboratory affect the result of an experiment there is a problem and the results are flawed or even useless; if local conditions fail to affect the outcome of fieldwork there too is a fundamental problem. Lorimer and Spedding, in this issue, discuss the character

12 S. Schaffer, 'Physics laboratories and the Victorian country house', in Making Space for Science (ed. J. Agar and C. Smith), London, 149-80.

13 Schaffer, op. cit. (12), 152.

14 Schaffer, op. cit. (12), 153.

15 D. Outram, 'New spaces in natural history', in Cultures of Natural History (ed. N. Jardine, J. Secord and E. Spary), Cambridge, 1996, 249-65.

16 R. Kohler, 'Place and practice in field biology', History of Science (2002), xl, 191.

17 Kohler, op. cit. (16), 192. See also R. Kohler, Landscapes and Labscapes: Exploring the Lab-Field Border in Biology, Chicago, 2002. 
of place and the performance of science in their account of a family's field trip to the Parallel Roads of Glen Roy.

In Kohler's extended study of early twentieth-century American biology he demonstrates the shifting epistemic valuing of the lab and the field - what he himself terms a 'cultural geography'. ${ }^{18}$ For instance, around 1900 he traces a reaction against amateur, descriptive and field-based natural history towards the laboratory ideals of genetics. Whilst some found themselves out in the scientific cold, others - particularly the plant physiologists, evolutionists and ecologists - were forced to make difficult decisions as to their preferred places of scientific investigation. Other good work has similarly considered the cultural geography of inclusion and exclusion in science. As Shapin documented the elite social geography of experimental philosophy in seventeenthcentury England, Larry Stewart has pointed to the alternative sites of scientific consumption in early modern London, such as the hospital and the coffee house, spaces serving those otherwise denied access to current thinking on astronomy, mathematics and navigation. ${ }^{19}$ Barbara Maria Stafford, meanwhile, juxtaposes two other spaces: the eighteenth-century chemistry laboratory and the 'collapsible tent and hastily assembled platform' of the quack. This 'anti-laboratory' was a temporary space lacking the respectability of Enlightenment learning, but its '[p]oster advertisement, skull, coffer of potions, and falsified documents' nonetheless mattered greatly to the ordinary inhabitants of the provinces, culturally far removed from elite learning. ${ }^{20}$

As historians and geographers have shown, boundaries of scientific inclusion and exclusion have long plagued those keen to contribute to debate. Anne Secord has famously documented the ways that working men in late eighteenth-century Lancashire co-opted one everyday space at their ready disposal - the public house - so that they might engage in botanical debates in a social environment. ${ }^{21}$ Ann Shteir has provided a similar analysis of nineteenth-century women botanists, pointing to their habitation of a set of familiar spaces - the field, the parlour or the breakfast room, the bazaar - whilst they were increasingly marginalized from the spaces of the nascent botanical sciences, particularly from the meetings of scientific societies and the classrooms of universities. ${ }^{22}$

It is impossible here to give a good account of the full range of work that investigates the places of science. Whilst I have touched on the laboratory, the museum, the hospital and the field, as well as the less familiar scientific sites of the coffee house, the town square and the public house, there are many other excellent studies of the conversazione, the lecture hall, the garden, the ship, the cave and the body, to name but a few. ${ }^{23}$ Nonetheless, the previous discussion is hopefully sufficient to confirm the

18 Kohler, op. cit. (17), 58.

19 L. Stewart, 'Other centres of calculation, or, where the Royal Society didn't count: commerce, coffeehouses and natural philosophy in early modern London', BJHS (1999), 32, 133-53.

20 B. Stafford, Good Looking: Essays on the Virtue of Images, Cambridge, MA, 1997, 98.

21 A. Secord, 'Science in the pub: artisan botanists in early nineteenth-century Lancashire', History of Science (1994), 32, 269-315.

22 A. Shteir, Cultivating Women, Cultivating Science: Flora's Daughters and Botany in England, 1760-1860, Baltimore, 1996.

23 See, respectively, S. Alberti, 'Conversaziones and the Experience of Science in Victorian England', Journal of Victorian Culture (2003), 8, 208-30; S. Naylor, 'The field, the museum and the lecture hall: the 
contention that place is central to the making and remaking of science. As we have seen, the place in which science is pursued is central to the veracity of the knowledge produced. Such sites act as 'truth spots' ${ }^{24}$ - bringing certain actors together, keeping others out, facilitating particular practices and constraining others. Taking scientific claims 'back to their place of provenance, at which they were born, but from which they have escaped into the universal space of transcendental truth ${ }^{25}$ is surely then a fruitful task.

\section{Contextualizing science}

Laboratories, field sites, museums, caves and pubs are not the only spaces in and through which science has been conducted and historical geographies of science can be written. Whilst at the most immediate level science is always carried out in circumscribed localities, so too is it always situated in more general contexts. Indeed, it is often in relation to these broader tableaux that science itself is understood, as, for instance, civic science, Yorkshire botany, the Scottish Enlightenment, continental natural philosophy, even global science. Here, as in the last section, I want to consider the significance of these spatial contexts in the shaping of science and to highlight some of the key work that has taken these scales seriously.

Beyond the intimacy of the laboratory, the lecture hall or the public house, perhaps the most immediately relevant context is the town or city, the urban, to which we might add the more abstract concept of the public or civic sphere. As Inkster and Morrell have demonstrated in their analysis of the variegated historical geography of science in Britain in the early nineteenth century, urban settings were crucial to the development of cultures of British science. ${ }^{26}$ The answer to the nature of the relationship between urban growth and scientific activity is not a simple one, however. In the British context some small towns - like Derby - exhibited a vigorous and visible scientific culture over this period; other larger settings, like Norwich or Bristol, were much more muted in their enthusiasm. It is therefore sensible to follow Inkster and Morrell's caution against imposing a single theoretical explanation, and develop instead a series of historical geographies of science and the urban. Good examples include Paul Elliott's work on natural philosophy in eighteenth-century Derby, ${ }^{27}$ and James Secord's analysis of the consumption of Robert Chambers's book Vestiges in Victorian

spaces of natural history in Victorian Cornwall', Transactions of the Institute of British Geographers (2002), 27, 494-513; J. Endersby, 'A garden enclosed: botanical barter in Sydney, 1818-39', BJHS (2000), 33, 313-34; R. Sorrenson, 'The ship as a scientific instrument in the eighteenth century', in H. Kuklick and R. Kohler (eds.), 'Science in the field', Osiris (1996), 11, 221-36; M. Shortland, 'Darkness visible: underground culture in the golden age of geology', History of Science (1994), 32, 1-61; C. Lawrence and S. Shapin (eds.), Science Incarnate: Historical Embodiments of Natural Knowledge, Chicago, 1998.

24 T. Gieryn, 'Three truth-spots', Journal of the History of the Behavioral Sciences (2002), 38, 113-32.

25 Gieryn, op. cit. (24), 130.

26 I. Inkster and J. Morrell (eds.), Metropolis and Province: Science in British culture, 1780-1850, London, 1983.

27 P. Elliott, 'The birth of public science in the English provinces: natural philosophy in Derby, c. 1690-1760', Annals of Science (2000), 57, 61-100. 
Britain. ${ }^{28}$ Both authors show that complex constellations of politics, religion, social make-up, industry and economics fostered and also impeded scientific understandings and activities in different urban settings.

Historians and geographers have developed an appreciation of the relations between science and the public and civic sphere, often in tandem with their treatment of the urban geographies of scientific knowledge. Elliot's history of natural philosophy in Derby documents the public sphere's early emergence in the English provinces, due to a burgeoning middle-and leisured-class, the increasing availability of scientific knowledges through itinerant lecturers and printed accounts, and the relatively uncontroversial nature of science as a subject for polite discourse. ${ }^{29}$ As Withers notes in his own consideration of science and the public sphere, 'scientific knowledge and politeness, both as means and ends, were promoted through experimentation, the use of instruments and the rhetoric of polite conversation designed to instruct and to amuse and also to confirm politeness as part of a "program of modernity" ${ }^{30}$ Finnegan, in this issue, makes an associative point, arguing in his paper that natural history societies in late Victorian Scotland helped build a provincial civic culture, one that saw itself aiding in the production of a moral citizenry and in broader urban progress. ${ }^{31}$

Beyond the town or city, science has often been understood within the context of a region-certainly in the case of the British county, the French département, the American state or the Canadian province. Scholars have noted the regionally inflected character of much science. In the British context, Sam Alberti has written extensively on the history of the life sciences in Yorkshire, Naylor on natural history and antiquarianism in Cornwall, Steven Shapin on Staffordshire, and Lorimer on highland Scotland, to give just a few examples. ${ }^{32}$ Whilst differences were assuredly there, what is perhaps most interesting for historians and historical geographers is the attempt by regional scientists to distinguish themselves from others working elsewhere, whilst tempering their claims to distinctiveness with assertions that their work was of national significance. Cornish antiquarians, for instance, mobilized their 'inductive science' to demarcate their county as a pre-eminent space of prehistoric enquiry - unsurpassed by any other region of Britain - whilst at the same time calling for antiquarians elsewhere

28 J. A. Secord, Victorian Sensation: The Extraordinary Publication, Reception, and Secret Authorship of Vestiges of the Natural History of Creation, Chicago, 2000.

29 Elliot, op. cit. (27), 96.

30 C. W. J. Withers, 'Towards a history of geography in the public sphere', History of Science (1998), 36, 49. See also Martin Rudwick's consideration of the relations between the public and private sphere - what he terms a 'scale of "relative privacy"' - in his work on Charles Darwin in London: M. Rudwick, "Charles Darwin in London: the integration of public and private science', Isis (1982), 73, 187.

31 See also C. Withers and D. Finnegan, 'Natural history societies, fieldwork and local knowledge in nineteenth-century Scotland: towards a historical geography of civic science', Cultural Geographies (2003), $10,334-53$.

32 S. J. M. M. Alberti, 'Amateurs and professionals in one county: biology and natural history in late Victorian Yorkshire', Journal of the History of Biology (2001), 34, 115-47; S. Naylor, 'Collecting quoits: field cultures in the history of Cornish antiquarianism', Cultural Geographies (2003), 10, 309-33; S. Shapin, 'The Pottery Philosophical Society, 1819-1835: an examination of the cultural uses of provincial science', Science Studies (1972), 2, 311-36; H. Lorimer, 'Telling small stories: spaces of knowledge and the practice of geography', Transactions of the Institute of British Geographers (2003), 28, 197-217. 
to pay attention to their work and to consider their findings as part of a broader national endeavour.

These politics of place also then tempered the production of science in national contexts. States have used science both to understand and to intervene in the affairs of the nation, as well as to engage in geopolitical struggles with their competitors, whether that be in an intellectually competitive way or to help them gain economic, political or military advantage over others. For Livingstone, the 'complicity of science in the constitution of senses of regional selfhood is particularly plain in enterprises that have had national labels appended to them-national laboratories, national surveys, national academies of science, and the like'. ${ }^{33}$ Philip Pauly's recent book provides us with a good example of this. In it he tracks the complex relations between American biology and the building of an American nation, a prosperous American people and a productive American nature. Within this he pays special attention to institutions such as the Woods Hole Marine Biological Laboratory in Massachusetts and the way that it 'became a center for an American biology'. ${ }^{34}$ Noting the importance other countries have placed on 'national laboratories' like Woods Hole - particularly France - Livingstone goes on to note that '[a]gain and again, national laboratories have given expression to a craving for national unity and afforded the state the opportunity to put its technical glories on display' ${ }^{35}$

Of course, national unity could be achieved in more ways than through the construction of institutional centres of learning and research. Returning to the American example, one of the key contributions made by science to the realization of the American nation was Lewis and Clark's cartographic survey of the Missouri in the early nineteenth century. Their mapping of the Louisiana Territory laid the foundations for Frederick Jackson Turner's 'frontier thesis' in the late nineteenth century and so was integral to 'the foundational narratives which ground U.S. identity' ${ }^{36}$ The United States Geological Survey played a later but no less important role, as did the Ordnance Trigonometrical Survey-and its spin-off the Geological Survey - in early nineteenth-century Britain, and the Geological Survey of Canada late in the century. ${ }^{37}$

Visualizing and managing a nation's own territory, resources and populace were key tasks for the scientist in the employ of the state. Helping a state compete with others was another, no less important, role. Consider for instance the role played by Sir Joseph Banks in the furtherance of the British Empire. Banks and his fellow neo-mercantilists effectively linked the apparatus of the state to the course of imperial expansion by harnessing the power of bodies such as the Royal Navy and the Privy Council

33 Livingstone, op. cit. (1), 124.

34 P. Pauly, Biologists and the Promise of American Life: From Meriwether Lewis to Alfred Kinsey, Princeton, 2000, 146.

35 Livingstone, op. cit. (1), 124.

36 R. Mayhew, 'Review article: textual editing and the construction of geography's history: the vexed question of the definitive', Journal of Historical Geography (2004), 30, 560. More generally, see S. Schulten, The Geographical Imagination in America, 1880-1950, Chicago, 2001.

37 B. Braun, 'Producing vertical territory: geology and governmentality in late Victorian Canada', Ecumene (2000), 7, 7-46. 
Committee for Trade. ${ }^{38}$ Banks's botanical work, whilst part of Cook's voyage to the southern Pacific, was instrumental in demonstrating the potential for new British settlements and penal colonies in Australia. Indeed, the widespread incorporation of scientific practitioners-botanists, ethnologists, astronomers, geologists and the like - into military expeditions from the eighteenth century onwards highlights a very conscious decision on the part of national governments to harness science for geopolitical ends.

There are numerous other ways in which we might consider the histories of science from its broad geographical contexts. Much work seems to remain safely within national boundaries but there is assuredly more to do on the varied practice and reception of science in different national contexts. A good example of work that has attempted this is the edited collection of essays Disseminating Darwinism, which considers Darwinism's treatment across the English-speaking world. ${ }^{39}$ Dritsas's paper in this issue is another welcome contribution, where he traces the very international geographies of the nineteenth-century Zambesi Expedition and the movement of its collections. More also remains to be done on the international and global characters of science - the ways in which science has worked (or indeed has not) across and beyond national boundaries, and the ways the very labels 'international' and 'global' have been constructed as terms to be aspired to or as problems to be faced.

\section{Cartographies of science}

Whilst sites, regions and nations are vital components of the histories of science it is important that we do not overlook other less obvious geographies. I want to move on now to consider a set of such geographies - not the spaces in which science occurs, but the geographies of science itself. How, for instance, has science embodied different spatial preconceptions in its work? How has science produced particular understandings of space as a quantity found in nature? How have particular spaces and spatialities impacted upon the formulation of scientific theories?

Alexander von Humboldt, the nineteenth-century Prussian scientific polymath, is a good person with whom to consider some of these questions. Humboldt has become famous for his emphasis on both empirical measurement and the generation of universal laws of nature. In particular he was a strong advocate of the use of mapping technologies to bring out natural commonalities. To facilitate his investigations Humboldt pioneered the isoline technique of cartography, enclosing and joining areas of equal value, whether pertaining to barometric pressure, temperature or vegetation type. ${ }^{40}$ These lines were the product of averaging and interpolation, the drawing of which "constituted an act of faith in both the physical "co-operation of forces" and in

38 J. Gascoigne, Science in the Service of Empire: Joseph Banks, the British State and the Uses of Science in the Age of Revolution, Cambridge, 1998.

39 R. Numbers and J. Stenhouse (eds.), Disseminating Darwinism: The Role of Place, Race, Religion, and Gender, Cambridge, 1999.

40 M. Nicolson, 'Alexander von Humboldt and the geography of vegetation', in Romanticism and the Sciences (ed. A. Cunningham and N. Jardine), Cambridge, 1990, 181. 
the emergence of global order out of local averages'. ${ }^{41}$ As such, isolines and the notion of equilibrium they supported 'prescribed a particular organization and dynamic of science'. ${ }^{42}$ In other words, isolines - themselves a technology with a geographical end - carried within themselves rules for the progress of Humboldt's scientific agenda. In turn,

Such lines demonstrated that there was, after all, in the necessary and unbridgeable gap between the artifice of mathematics or geometry and bodily, sensual, physical nature ... a shape of nature, which could at least in principle be more or less adequately drawn. ${ }^{43}$

Not only, then, did Humboldt's scientific practices embody spatial presuppositions, they also helped observers to consider the world through a geographical lens. Jane Camerini makes an associative point in her analysis of the role of maps in debates over evolution and biogeography in the mid-nineteenth century. ${ }^{44}$ She notes that in their struggles to demonstrate the existence of faunal provinces Charles Darwin and Alfred Russel Wallace made use of maps as mental tools as well as representational devices. Darwin, Camerini claims, 'employed the idea of regions as a conceptual scaffolding for a complex combination of geological, biological, and geographical phenomena', and that for Wallace, 'the map, a pictorial metaphor, served as a unifying framework for disparate information about insect, bird, and mammalian forms in their respective locations'. ${ }^{45}$

Wallace became famous for depicting and dividing the Asian and Australian biotas with a single line that became known as 'Wallace's line'. Here he followed a trend - if not started then encouraged by Humboldt - to employ mapping techniques as tools in debates about the origins and distribution of animal and plant life. Indeed, from the later eighteenth century it had become increasingly accepted that there were discernible patterns to the distribution of animal and plant life. For instance, and although they had been in use for some time, by the 1760s the terms 'flora', 'fauna' and 'region' began to be employed to designate the 'structural uniqueness and topographical limits of the entire population' contained in a geographical area. ${ }^{46}$ Whilst floras and faunas produced before the mid-eighteenth century did not necessarily imply any strict relationship between organism and place of residence, those written after the 1760s conveyed 'a certain comprehensiveness, a particular geographical region that had been thoroughly investigated and exhaustively catalogued' ${ }^{47}$

41 M. Dettelbach, 'Humboldtian science', in Cultures of Natural History (ed. N. Jardine, J. Secord and E. Spary), Cambridge, 1996, 298.

42 Dettelbach, op. cit. (41), 298.

43 M. Dettelbach, 'The face of nature: precise measurement, mapping, and sensibility in the work of Alexander von Humboldt', Studies in the History and Philosophy of the Biological and Biomedical Sciences (1999), 30, 490.

44 J. Camerini, 'Evolution, biogeography, and maps: an early history of Wallace's line', in Darwin's Laboratory: Evolutionary Theory and Natural History in the Pacific (ed. R. MacLeod and P. Rehbock), Honolulu, 1994, 70-109.

45 Camerini, op. cit. (44), 79 and 90 respectively.

46 Janet Browne, The Secular Ark: Studies in the History of Biogeography, New Haven, 1983, 27.

47 Browne, op. cit. (46), 29. 
By Wallace's day, a whole range of geographical terms were available to the naturalist: 'new terms, such as isotherms, life zones, plant community, vegetation assemblage and species range, gave additional evidence of the increasing role of map-based concepts in the study of geographical distribution' ${ }^{48}$ Other terms were borrowed from geopolitical and political-arithmetic thinking: animal and plant units existed as 'nations', 'states', 'provinces', and 'kingdoms', occupied 'stations' and 'outposts' and could even be 'natives' or 'colonists'. 'This was', Browne notes, 'the muscular language of expansionist power'. ${ }^{49}$ As such, then, whilst nineteenth-century naturalists claimed to identify distinct geographies in the chaos of nature, so too did they impose their own political geographical preoccupations on the natural world.

\section{Conclusions}

There are many other ways of thinking geographically about the history of science and given constraints on space I have only been able to discuss a few here, hint at others and been forced to ignore some altogether. For instance, and to invert the discussion in the last section, there are productive debates to be had on the affect of place on science. Rather than dwelling only on the ways in which science has written about place, we could fruitfully consider the ways landscapes, regions and places inform - consciously or not - scientific theories and practices. We might, in other words, pay attention to the biographies of place as we research the practices of science. ${ }^{50}$ Livingstone makes an associative injunction, where he calls for more attention to 'life geographies', arguing that a 'greater sensitivity to the spaces of a life could open up new and revealing ways of taking a measure of a life ${ }^{51}$ Employing Darwin as an example he suggests that the great man could be opened out in new ways through a focus on his various geographical lives: the Beagle Darwin, the Downe Darwin, the public Darwin, the private Darwin, the London Darwin and so on.

Other geographies of science we might detail are those characterized not by their fixity but by their transience or placelessness: the movements and circulations that help sustain the idea that science is not a localized activity but something beyond place and culture. Much has of course been written on the movement of scientific ideas, information and communications, technological objects, even people themselves. Indeed, Mayhew in this issue provides us with an innovative analysis of the networked but distantiated Republic of Letters in early modern geography. Other work has also highlighted the way scientific communities were built not through direct interactions but through networks of communication that stretched across regions, countries, even

48 Camerini, op. cit. (44), 77. Original emphasis.

49 J. Brown, 'Biogeography and empire', in Cultures of Natural History (ed. N. Jardine, J. Secord and E. Spary), Cambridge, 1996, 315.

50 For work that considers the affects of landscape on science, see J. Paradis, 'Darwin and landscape', in Victorian Science and Victorian Values: Literary Perspectives (ed. J. Paradis and T. Postlewait), New York, 1985, 85-110; S. Naylor, 'Discovering nature, re-discovering the self: natural historians and the landscapes of Argentina', Environment and Planning D: Society and Space (2001), 19, 227-47.

51 Livingstone, op. cit. (1), 183. Original emphasis. 
the globe. These studies consider the social contexts of correspondence networks ${ }^{52}$ as well as the material geographies of communication, as for instance Ogborn does in his analysis of the role of royal letters within the voyages of the English East India Company. ${ }^{53}$

This paper, then, provides only a brief and broad introduction to some of the ways that we might write the history of science from a historical geographical perspective. The following papers provide a much more sustained exposition of the range of empirical, conceptual and methodological issues pertinent to historical geography than I have been able to here. I hope, though, that this paper is sufficient to persuade readers of this journal that space is much more than just a container for scientific endeavour; rather, that geography has been central to the shaping of scientific cultures in a wide variety of ways, and that historical geography can be a rich resource for all those interested in producing nuanced accounts of science's history.

52 See, for instance, D. Lux and H. Cook, 'Closed circles or open networks? Communicating at a distance during the Scientific Revolution', History of Science (1998), 36, 179-211; A. Secord, 'Corresponding interests: artisans and gentlemen in nineteenth-century natural history', BJHS (1994), 27, 383-408.

53 M. Ogborn, 'Writing travels: power, knowledge and ritual on the English East India Company's early voyages', Transactions of the Institute of British Geographers (2002), 27, 155-71. 